Original Research Paper

\title{
Aplikasi Pupuk Organik dan NPK untuk Meningkatkan Pertumbuhan Vegetatif Melon(Cucumis melo L.)
}

\author{
Ahmad Raksun ${ }^{1 *}$, Lalu Japa ${ }^{1}$, I Gde Mertha ${ }^{1}$ \\ ${ }^{1}$ Pendidikan Biologi, Jurusan PMIPA FKIP Universitas Mataram
}

Article history

Received: 13 Desember 2018

Revised: 28 Desember 2018

Accepted: 8 Februari 2019

Published: 11 Februari 2019

*Corresponding Author: Ahmad Raksun,

Program Studi Pendidikan Biologi, Jurusan PMIPA

FKIP Universitas Mataram Email:

ahmadunram@unram.ac.id
Abstrak: Pupuk merupakan kebutuhan yang sangat vital bagi tanaman. Di dalam pupuk terkandung berbagai unsur hara yang sangat penting untuk mendukung pertumbuhan tanaman. Pemupukan tanaman dapat dilakukan dengan menggunakan pupuk sintetik maupun pupuk organik. Telah dilakukan penelitian tentang aplikasi pupuk organik dan pupuk NPK untuk meningkatkan pertumbuhan vegetatif melon yang bertujuan untuk mengetahui (1) pengaruh aplikasi pupuk organik terhadap pertumbuhan vegetatifmelon, (2)pengaruh aplikasi pupuk NPK terhadap pertumbuhan vegetatifmelon, (3)pengaruh interaksi pupuk organik dan pupuk NPK terhadap pertumbuhan vegetatifmelon.Dalam penelitian ini digunakan Rancangan Faktorial yang terdiri atas 2 faktor. Faktor pertama adalah dosis pupuk organik dan faktor kedua adalah dosis pupuk NPK. Perlakuan pupuk organik terdiri atas 4 level yaitu: $\mathrm{P}_{\mathrm{o}}=$ tampa pemberian pupukorganik (kontrol), $\mathrm{P}_{1}=$ pemberian $0,5 \mathrm{~kg}$ pupuk organik $/ 1 \mathrm{~m}^{2}$ lahan, $\mathrm{P}_{2}=$ pemberian $1,0 \mathrm{~kg}$ pupuk organik $/ 1 \mathrm{~m}^{2}$ lahan, $\mathrm{P}_{3}$ = pemberian $1,5 \mathrm{~kg}$ pupuk organik $/ 1 \mathrm{~m}^{2}$ lahan, Selanjutnya faktor pupuk NPK terdiri atas 5 level yaitu, $\mathrm{N}_{0}=$ tampa pemberian pupuk NPK (kontrol), $\mathrm{N}_{1}=$ pemberian 5 gram pupuk NPK/tanaman, $\mathrm{N}_{2}=$ pemberian 10 grampupuk $\mathrm{NPK} /$ tanaman, $\mathrm{N}_{3}=$ pemberian 15 grampupuk NPK/tanaman, $\mathrm{N}_{4}=$ pemberian 20 gr pupuk NPK/tanaman.Parameter pertumbuhan yang diukur adalahpanjang batang dan panjang daun melon, Data kuantitatif hasi pengukuran parameter di atas dianalisis dengan analisis sidik ragam.Dalam penelitian ini disimpulkan bahwa aplikasi pupuk organik berpengaruh sangat nyata terhadap pertumbuhan vegetatif melon. Aplikasi pupuk NPK berpengaruh sangat nyata terhadap pertumbuhan melon. Interaksi pupuk organik dan pupuk NPK tidak berpengaruh nyata terhadap pertumbuhan vegetatif melon.

Kata kunci : Pupuk organik, pupuk NPK, Pertumbuhan vegetatif melon

Abstract: Fertilizers are a very vital requirement for plants. Fertilizer contains various nutrients that are very important to support plant growth. Fertilizing plants can be done by using synthetic fertilizers or organic fertilizers. Research has been carried out on the application of organic fertilizer and NPK fertilizer to improve the vegetative growth of melons which aims to find out: (1) the effect of organic fertilizer on vegetative melon growth, (2) the effect of NPK fertilizer on vegetative growth of melons, (3) the effect of interaction between organic fertilizer and NPK fertilizer on vegetative melon growth. In this study a Factorial Design consisting of 2 factors was used. The first factor is the dose of organic fertilizer and the second factor is the dose of NPK fertilizer. The treatment of organic fertilizer consists of 4 levels, namely: $\mathrm{P}_{\mathrm{o}}=$ without giving organic fertilizer (control), $\mathrm{P}_{1}=$ giving $0.5 \mathrm{~kg}$ organic fertilizer $/ 1 \mathrm{~m}^{2}$ land, $\mathrm{P}_{2}=$ giving $1.0 \mathrm{~kg}$ organic fertilizer $/ 1 \mathrm{~m}^{2}$ land, $\mathrm{P}_{3}=$ giving $1.5 \mathrm{~kg}$ of organic fertilizer/ $1 \mathrm{~m}^{2}$ land, then NPK fertilizer factor consists of 5 levels, namely $\mathrm{N}_{0}=$ without NPK fertilizer (control), $\mathrm{N}_{1}$ = giving 5 grams of NPKfertilizer/plant, $\mathrm{N}_{2}$ = giving 10 grams of NPK fertilizer/plant, $\mathrm{N}_{3}=$ giving 15 grams of NPK fertilizer/plant, $\mathrm{N}_{4}=$ giving 20 grams of NPK fertilizer/plants. Thegrowth 
parameters were stem length and melon leaf length.Data were analyzed by using ANOVA. In this reseach concluded thatthe application of organic fertilizer hasa significant effect on the vegetative growth of melon. The application of NPK fertilizer has a significant effect on the growth of melon. The interaction of organic fertilizer and NPK fertilizer did not significantly affect the growth of melon.

Keywords : Organic fertilizer, NPK fertilizer, vegetative melon growth

\section{Pendahuluan}

Pupuk adalah kebutuhan yang sangat vital bagi tanaman. Pupuk sangat penting untuk pertumbuhan dan kelangsungan hidup tanaman. Di dalam pupuk terkandung berbagai unsur hara yang sangat penting bagi tanaman. (Yuliarti, 2009). Pemupukan tanaman dapat dilakukan dengan menggunakan pupuk sintetik maupun pupuk organik. Pupuk sintetik yang sering digunakan petani adalah pupuk urea dan NPK, sedangkan pemupukan menggunakan pupuk organik masih jarang dilakukan. Peggunaan input kimiawi (pupuk dan festisida sintetik) dengan dosis tinggi tidak hanya berpengaruh menurunkan tingkat kesuburan tanah, tetapi juga mengakibatkan pada merosotnya keanekaragaman hayati, meningkatnya serangan hama dan penyakit, timbulnya hama yang resisten dan berkembangnya organisme parasit. Selain itu dampak negatif dari penggunaan infut kimiawi tidak hanya terbatas pada daerah pemakaian tetapi dapat menjadi makin luas melalui komponen rantai makanan seperti air minum, sayuran, buah-buahan dan produk-produk lain yang terkontaminasi (Zulkarnain, 2014).

Penggunaan pupuk organik memiiki berbagai keunggulan dibandingkan pupuk kimia diantaranya dapat mengatur sifat tanah dan dapat berperan sebagai penyangga persediaan unsur hara bagi tanman sehingga pupuk ini dapat mengembalikan kesuburan tanah (Yuliarti, 2009). Penggunaan pupuk organik dapat meningkatkan pertumbuhan tanaman. Perlakuan pupuk organik kotoran ayam 15 ton per hektar dalam larikan mampu meningkatkan produksi jagung manis hingga $21,3 \%$ dengan produksi yang mencapai 14,67 ton per hektar dibandingkan dengan pupuk anorganik (kontrol) (Rizqullah et al, 2017). Penggunaan pupuk organik berpengaruh nyata terhadap parameter tinggi batang tanaman, diameter batang, indeks luas daun, panjang tongkol dan bobot segar tongkol per hektar tanaman jagung manis (Nurcahya et al., 2017). Perlakuan perendaman bibit rumput laut dalam larutan pupuk organik cair memberikan dampak positif terhadap pertumbuhan bibit rumput laut Euchema cottonii (Karnan et al., 2015). Berdasarkan uraian di atas maka peneliti melakukan penelitian tentang pengaruh pupuk organik dan pupuk NPK terhadap pertumbuhan vegetatif melon. Adapun tujuan dilaksanakannya penelitian ini adalah untuk mengetahui: (1) pengaruh pupuk organik terhadap pertumbuhan vegetatif melon, (2) pengaruh pupuk NPK terhadap pertumbuhan vegetatif melon, (3 pengaruh interaksi pupuk organik dan pupuk NPK terhadap pertumbuhan vegetatif melon

\section{Bahan dan Metode}

Bahan-bahan yang digunakan dalam penelitian ini adalah pupuk organik, pupuk NPK, kertas label, benih melon, air, bahan-bahan pembuatan rumah kaca sederhana (bambu, tali rapia, besi paku dan kertas transparan),mulsa plastik, insektisidadan fungisida. Selanjutnya alat yang digunakan adalah pot pembibitan, parang, palu, cangkul,artco dorong, ember plastik, timbangan, alat tulis menulis, gunting, karung goni,karung nilon, terpal, meteran, sekop dan hand sprayer

Rancangan penelitian ini adalah rancangan faktorial yang terdiri atas 2 faktor. Faktor pertama adalah dosis pupuk organik dan faktor kedua adalah dosis pupuk NPK. Dosis pupuk organik terdiri atas 4 level yaitu: $\mathrm{P}_{0}=$ tampa pemberian pupuk organik (kontrol), $\mathrm{P}_{1}=$ pemberian $0,5 \mathrm{~kg}$ pupuk organik $/ 1 \mathrm{~m}^{2}$ lahan, $\mathrm{P}_{2}=$ pemberian $1,0 \mathrm{~kg}$ pupuk organik $/ 1 \mathrm{~m}^{2}$ lahan, $\mathrm{P}_{3}=$ pemberian $1,5 \mathrm{~kg}$ pupuk organik $/ 1 \mathrm{~m}^{2}$ lahan. Selanjutnya faktor pupuk NPK terdiri atas 5 level yaituN $\mathrm{N}_{0}=$ tampa pemberian pupuk NPK, $\mathrm{N}_{1}=$ pemberian 5 gram pupuk NPK/tanaman, $\mathrm{N}_{2}=$ pemberian 10 gram pupukNPK/tanaman, $\mathrm{N}_{3}=$ pemberian 15 gram 
pupukNPK/tanaman, $\mathrm{N}_{4}=$ pemberian 20 gram pupukNPK/tanaman.

Parameter pertumbuhan yang diukur adalahpanjang batang dan panjang daun melon umur 24 hari setelah tanam. Data kuantitatif hasi pengukuran parameter di atas dianalisis dengan analisis sidik ragam (Gomez dan Gomez, 1995; Toutenburg and Shalabh, 2009). Adapun rumus yang digunakan adalah:

$$
\mathrm{F}_{\text {hitung }}=\frac{\text { Kuadrat Tengah Perlakuan }}{-----------------------}
$$

\section{Hasil dan Pembahasan}

Data hasil pengukuran panjang batang tanaman melon menunjukkan bahwa rerata panjang batang tanaman melon tertinggi adalah $73 \mathrm{~cm}$ terdapat pada perlakuan $\mathrm{P}_{2} \mathrm{~N}_{3}$ (kombinasi perlakuan $1,0 \mathrm{~kg}$ pupuk organik per $1 \mathrm{~m}^{2}$ lahan dan 15 gram pupuk NPK per tanaman). Selanjutnya rerata panjang batang melon terendah adalah $58 \mathrm{~cm}$ terdapat pada perlakuan $\mathrm{P}_{0} \mathrm{~N}_{0}$ dan perlakuan $\mathrm{P}_{0} \mathrm{~N}_{1}$. Hasil analisis sidik ragam menunjukkan bahwa perlakuan pupuk organik berpengaruh sangat nyata terhadap panjang batang melon. Perlakuan pupuk NPK berpengaruh sangat nyata terhadap panjang batang melon. Interaksi pupuk organik dan pupuk NPK tidak berpengaruh nyata terhadap panjang batang melon. Data hasil pengukuran panjang batang melon umur 24 hari setelah tanam adalah sebagai berikut:

Tabel 1. Rerata Panjang Batang Melon Akibat Perlakuan Pupuk Organik dan NPK

\begin{tabular}{|c|c|c|c|}
\hline Perlakuan & $\begin{array}{c}\text { Rerata panjang batang } \\
\text { melon }(\mathrm{cm})\end{array}$ & Perlakuan & $\begin{array}{c}\text { Rerata panjang batang } \\
\text { melon }(\mathrm{cm})\end{array}$ \\
\hline $\mathrm{P}_{0} \mathrm{~N}_{0}$ & 58 & $\mathrm{P}_{2} \mathrm{~N}_{0}$ & 61 \\
\hline $\mathrm{P}_{0} \mathrm{~N}_{1}$ & 58 & $\mathrm{P}_{2} \mathrm{~N}_{1}$ & 66 \\
\hline $\mathrm{P}_{0} \mathrm{~N}_{2}$ & 61 & $\mathrm{P}_{2} \mathrm{~N}_{2}$ & 69 \\
\hline $\mathrm{P}_{0} \mathrm{~N}_{3}$ & 62 & $\mathrm{P}_{2} \mathrm{~N}_{3}$ & 73 \\
\hline $\mathrm{P}_{0} \mathrm{~N}_{4}$ & 57 & $\mathrm{P}_{2} \mathrm{~N}_{4}$ & 63 \\
\hline $\mathrm{P}_{1} \mathrm{~N}_{0}$ & 59 & $\mathrm{P}_{3} \mathrm{~N}_{0}$ & 48 \\
\hline $\mathrm{P}_{1} \mathrm{~N}_{1}$ & 60 & $\mathrm{P}_{3} \mathrm{~N}_{1}$ & 56 \\
\hline $\mathrm{P}_{1} \mathrm{~N}_{2}$ & 61 & $\mathrm{P}_{3} \mathrm{~N}_{2}$ & 58 \\
\hline $\mathrm{P}_{1} \mathrm{~N}_{3}$ & 64 & $\mathrm{P}_{3} \mathrm{~N}_{3}$ & 59 \\
\hline $\mathrm{P}_{1} \mathrm{~N}_{4}$ & 56 & $\mathrm{P}_{3} \mathrm{~N}_{4}$ & 56 \\
\hline
\end{tabular}

Selain panjang batang melon, dilakukan juga pengukuran panjang daun melon sebagai parameter pertumbuhan melon. Data hasil pengukuran panjang daun melon menunjukkan bahwa rerata panjang daun melon tertinggi adalah $17,7 \mathrm{~cm}$ terdapat pada perlakuan $\mathrm{P}_{2} \mathrm{~N}_{3}$ (kombinasi perlakuan $1,0 \mathrm{~kg}$ pupuk organik per $1 \mathrm{~m}^{2}$ lahan dan 15 gram pupuk NPK per tanaman). Data panjang daun melon terendah adalah $15,1 \mathrm{~cm}$, terdapat pada perlakuan $\mathrm{P}_{3} \mathrm{~N}_{0}$. Hasil analisis sidik ragam menunjukkan bahwa perlakuan pupuk organik berpengaruh sangat nyata terhadap panjang daun tanaman melon, perlakuan pupuk NPK berpengaruh sangat nyata terhadap panjang daun tanaman melon dan Interaksi pupuk organik dan pupuk NPK tidak berpengaruh nyata terhadap panjang daun melon. Data hasil pengukuran panjang daun melon terdapat pada tabel 2 . 
Tabel 2. Rerata Panjang Daun Melon Akibat Perlakuan Pupuk Organik dan NPK

\begin{tabular}{|c|c|c|c|}
\hline Perlakuan & $\begin{array}{c}\text { Rerata panjang daun } \\
\text { melon }(\mathrm{cm})\end{array}$ & Perlakuan & $\begin{array}{c}\text { Rerata panjang daun } \\
\text { melon }(\mathrm{cm})\end{array}$ \\
\hline $\mathrm{P}_{0} \mathrm{~N}_{0}$ & 15,4 & $\mathrm{P}_{2} \mathrm{~N}_{0}$ & 16,9 \\
\hline $\mathrm{P}_{0} \mathrm{~N}_{1}$ & 15,9 & $\mathrm{P}_{2} \mathrm{~N}_{1}$ & 17,1 \\
\hline $\mathrm{P}_{0} \mathrm{~N}_{2}$ & 16,1 & $\mathrm{P}_{2} \mathrm{~N}_{2}$ & 17,6 \\
\hline $\mathrm{P}_{0} \mathrm{~N}_{3}$ & 16,4 & $\mathrm{P}_{2} \mathrm{~N}_{3}$ & 17,7 \\
\hline $\mathrm{P}_{0} \mathrm{~N}_{4}$ & 15,3 & $\mathrm{P}_{2} \mathrm{~N}_{4}$ & 17 \\
\hline $\mathrm{P}_{1} \mathrm{~N}_{0}$ & 15,8 & $\mathrm{P}_{3} \mathrm{~N}_{0}$ & 15,1 \\
\hline $\mathrm{P}_{1} \mathrm{~N}_{1}$ & 16,2 & $\mathrm{P}_{3} \mathrm{~N}_{1}$ & 15,3 \\
\hline $\mathrm{P}_{1} \mathrm{~N}_{2}$ & 16,3 & $\mathrm{P}_{3} \mathrm{~N}_{2}$ & 15,4 \\
\hline $\mathrm{P}_{1} \mathrm{~N}_{3}$ & 17 & $\mathrm{P}_{3} \mathrm{~N}_{3}$ & 15,7 \\
\hline $\mathrm{P}_{1} \mathrm{~N}_{4}$ & 16 & $\mathrm{P}_{3} \mathrm{~N}_{4}$ & 15,2 \\
\hline
\end{tabular}

Hasil analisis data menunjukkan bahwa aplikasi pupuk organik pada lahan pertanian berpengaruh sangat nyata terhadap panjang batang dan panjang daun tanaman melon. Adanya pengaruh sangat nyata perlakuan pupuk organik terhadap semua parameter pertumbuhan melon dimungkinkan karena pupuk organik mengandung berbagai unsur hara makro dan mikro yang penting untuk mendukung pertumbuhan tanaman. Hakim et al.,(1986) menjelaskan bahwa pupuk yang mengandung berbagai unsurhara baik makro maupun mikro, bila diberikan padatanaman dalam jumlah yang optimal akan meningkatkan pertumbuhan tanaman. Selanjutnya Sutedjo (2010) menyatakan bahwa penggunaan pupuk organikdapat meningkatkan kandungan unsur hara serta memperbaiki struktur tanah karena dapat merangsang perkembangan jasad renik di dalam tanah. Dengan demikian apabila diberikan dalam jumlah yang optimal akan dapat meningkatkan laju fotosintesis dan pertumbuhan tanaman

Hasil penelitian ini sejalan dengan hasil penelitian yang dilakukan peneliti lainnya. Pemberian pupuk organik kompos berpengaruh nyata terhadap tinggi tanaman, umur berbunga, umur panen dan berat buah cabai rawit (Maruli et $a l, 2012$ ). Pupuk organic mikroorganisme local medianasi, batang pisang dan ikan tongkol memberikan pengaruhnya taterhadap pertumbuhan tanaman sawi (Brassicajuncea) dengan dosisterbaik $100 \mathrm{ml} /$ liter air (10\%). (Mursalim, 2018). Pemberian pupuk organik cair (POC) berpengaruh terhadap pertumbuhan tanaman selada dan pemberian pupuk organik cair konsentrasi 3 $\mathrm{m} / /$ liter air padajarak tanam $25 \mathrm{cmx} 25 \mathrm{~cm}$ memperlihatkan hasil yang terbaik dalam meningkatkan pertumbuhan dan produksi tanaman selada (Guna et al., 2018). Aplikasi beberapa pupuk organik pada tanaman caisim (Brassica campestris var. chinensis L) dapat meningkatkan tinggi batang, panjang daun, lebar dan berat basah daun (Abuyamin 2016).Perlakuan pupuk orgtanik cair limbah ikan berpengaruh terhadap pengamatan panjang tanaman dan pengamatan jumlah daun. Kombinasi antara pupuk cair limbah ikan dan Trichoderma sp. menunjukkan interaksi terhadap semua variabel pengamatan yaitu panjang tanaman, jumlah daun, diameter batang, bobot basah brangkasan dan bobot kering brangkasan tanaman Kailan (Abrordan Harjo, 2018).

Tumbuhan mengambil unsur hara dari tanah. Sebagian besar mineral tersedia secara alami di dalam tanah melalui proses pelapukan batuan induk. Namun demikian tidak semua unsur yang diperlukan tumbuhan bersumber dari pelapukan batuan, sebagai contoh unsur fosfor dan nitrogen berasal dari bangkai tumbuhan dan bangkai organisme lainnya di permukaan dan di dalam tanah, setelah melalui proses panjang pengomposan dan penguraian oleh mikro organisme. Oleh karena itu, komposisi tanah yang paling ideal untuk pertumbuhan dan perkembangan tumbuhan secara normal harus tersedia bahan organik tidak kurang dari $15 \%$. Bahan organik ini adalah sumber unsur hara Nitrogen dan Fosfor. Dalam hal ini, peran bakteri sebagai pengurai 
sangat penting sampai unsur hara fosfor dan nitrogen siap untuk diserap oleh tumbuhan. Unsur hara nitrogen juga dapat tersedia secara alami karena peran bakteri dan cyano bakteri tertentu yang mempunyai kemampuan memfiksasi gas nitrogen bebas di atmosfer. (Knox et al, 1994)

Perlakuan pupuk NPK juga berpengaruh sangat nyata terhadap semua parameter pertumbuhan yang diukur. Hal ini disebabkan karena unsur hara $\mathrm{N}, \mathrm{P}$ dan $\mathrm{K}$ merupakan unsur hara makro bagi tumbuhan. Yousuf et al. (2014) melaporkan, bahwa tanaman coriander (Coriandrum sativum L.) menghasilkan produksi biji tertinggi (2,06 ton/ha pada tahun 2008-2009 dan 2,09 ton/ha pada tahun 2009-2010) diperoleh dari aplikasi moderat $\mathrm{N}, \mathrm{P}, \mathrm{K}$, dan $\mathrm{S}$ berturut-turut: $70,50,30$, dan $20 \mathrm{~kg} / \mathrm{ha}$, dan produksi menurun dengan dosis yang lebih tinggi unsur hara tersebut. Produksi biji tertinggi seperti itu terkait dengan jumlah maksimum cabang primer per tanaman $(8,65)$ tercatat pada penggunaan N70P50K30S20 $\mathrm{kg} / \mathrm{ha}$. Unsur hara $\mathrm{N}, \mathrm{P}, \mathrm{K}$, dan $\mathrm{S}$ berperan secara nyata meningkatkan pertumbuhan dan perkembangan tanaman coriander, percabangan maksimum yang berimplikasi pada produksi biji yang melimpah. Tanaman coriander tertinggi $(74.20 \mathrm{~cm}$ dan $76.43 \mathrm{~cm})$ juga tercatat pada perlakuan (N70P50K30S20 kg/ha) dalam dua tahun berturut-turut 2008-2009 dan 20092010.Penggunaan pupuk NPK pada semai gmelina dilaporkan oleh Waris dan Fathia (2010), bahwa pupuk NPK berpengaruh nyata terhadap pertumbuhan tinggi dan diameter batang. Perlakuan kombinasi NPK 10 gr dan kompos 30 gr memberikan pengaruh paling nyata dan respon pertumbuhan tertinggi terhadap kontrol yaitu $70,08 \%$ atau setara dengan rata-rata pertumbuhan sebesar 7,56 cm terhadap kontrol.Dosis pupuk NPK berpengaruh terhadap pertumbuhan dan hasil tanaman bunga matahari (Vaniza dan Sitawi, 2018).

\section{Kesimpulan}

Berdasarkan hasil analisis data dan pembahasan pada penelitian ini maka dapat disimpulkan bahwa: (1) aplikasi pupuk organik berpengaruh sangat nyata terhadap pertumbuhan vegetatif melon, (2) aplikasi pupuk NPK berpengaruh sangat nyata terhadap pertumbuhan vegetatif melon (3) interaksi pupuk organik dan pupuk NPK tidak berpengaruh nyata terhadap pertumbuhan vegetatif melon, (4) dosis optimum pupuk organik untuk tanaman melon adalah $1,0 \mathrm{~kg}$ pupuk organik per $1 \mathrm{~m}^{2}$ lahan (5) dosis optimum pupuk NPK adalah 15 gram per tanaman. Berdasarkan hasil penelitian ini direkomendasikan kepada petani melon di Pulau lombok agar menggunakan pupuk organik $1,0 \mathrm{~kg}$ per $1 \mathrm{~m}^{2}$ lahan dan pupuk NPK 15 gram per tanaman.

\section{Ucapan TerimaKasih}

Termakasih yang sebesar-besarnya tim penulis sampaikan kepada Rektor Universitas Mataram yang telah memfasilitasi pelaksanaan penelitian ini dengan menyediakan dana penelitian. Terimakasih juga kami sampaikan kepada semua pihak yang telah membantu pelaksanaan penelitian ini

\section{Daftar Pustaka}

Abror, M. \& R.P.Harjo. (2018). Efektifitas pupuk organi cair Limbah Ikan dan Trichodermasp. Terhadap Pertumbuhan dan Hasil Tanaman Kaikin (Brassica oleraceae sp.). Agrosains dan Teknologi, 3 (1): 1 - 12

Abuyamin (2016). Pengaruh Pemberian Urin Kelinci dan Kompos terhadap Pertumbuhan dan Hasil Tanaman Caisim (Brassica juncea L.). Plumula, 5 (1) : 69 - 79

Gomez K.A. \& A.A. Gomez. (1995). Prosedur Statistik Untuk penelitian Pertanian Edisi Kedua Penerjemah: Endang Syamsudin dan Justika S. Baharsyah. UI Press. Jakarta.

Guna, H.I., Armaini \& F. Puspita.(2018). Alikasi Pupuk Organik Cair (POC) terhadap Pertumbuhan dan Produksi Tanaman Selada (Lactuca sativaL.) pada Jarak Tanam yang Berbeda JOM Paperta, 5 (1): 1 - 13

Hakim, N. M., Y. Nyakpa, A. M.Lubis,S.G. Nugroho, M.R. Saul, M. A. Diha, G. B. Hongdan H. \&H. Bailey (1986). Dasar- 
dasarIlmu Tanah. Universitas Lampung. Lampung.

Karnan, A. Raksun \& L. Japa. (2015). Respon Pertumbuhan Rumput Laut Euchema cottonii terhadap Pemberian Pupuk Organik Cair di Teluk Ekas Lombok Timur. Jurnal Biologi Tropis, 15 (1): 39 - 46

Knox, B., P. Ladiges, B. Evans. (1994). Biology. McGraw-Hill Book Company Australia Pty Limited. Australia.

Maruli, Ernita dan H. Gultom. (2012). Pengaruh Pemberian NPK Grower dan Kompos terhadap Pertumbuhan dan Produksi Tanaman Cabai Rawit (Capsicum frustencen L.). J.Dinamika Pertanian, 17 (3) :149 155

Mursalim, I. (2018). Pengaruh Penggunaan Pupuk Organik Mikroorganisme Lokal Media Nasi, Batang Pisang dan Ikan Tongkol terhadap Pertumbuhan Tanaman Sawi (Brassicajuncea). Jurnal Biotek, 6 (1): 32 $-45$

Nurcahya, A.O., N. Herlina \& B. Guritno. (2017). Pengaruh Macam Pupuk Organik dan Waktu Aplikasi terhadap Pertumbuhan dan Hasil Jagung Manis (Zea mays saccharata Sturt). Produsi Tanaman, 5 (9): 1476 -1482

Rizqullah, H., Sitawati dan B. Guritno. (2017). Pengaruh Macam dan Cara Aplikasi Pupuk Organik terhadap Pertumbuhan dan Produksi Tanaman Jagung Manis. Produksi Tanaman, 5 (3): 387 - 389

Sutedjo,H. (2010). Petunjuk Penggunaan Pupuk. Penebar Swadaya. Jakarta.

Teutenburg, H. \& Shalabh. (2009). Statistical Analysis of Designed Experiment. Third Edition. Springer. New York

Vaniza \& Sitawi (2018). Pengaruh Waktu Pinching dan Dosis Pupuk NPK terhadap Pertumbuhan dan Hasil Bunga Matahari
Varietas Sungold. Produksi Pertanian, 6 (5): $685-692$

Waris, B. \& Fathia, N. (2010). Pengaruh Pupuk NPK dan Kompos terhadap Pertumbuhan Semai Gmelina pada Media Tanah Bekas Tambang Emas (Tailing). Ilmu Pertanian Indonesia, 16 (2): 123 - 129

Yousuf, M.N. S. Brahma, M. M. Kamal, S. Akter, \& M. E. K. Chowdhury. (2014). Effect of Nitrogen, phosphorus, Potassium, and Sulphur on the Growth and Seed Yield Coriander (Coriandrum sativum L.). Bangladesh Journal. Of Agricultural Reseach, 39(2): 303-309.

Yuliarti, N. (2009). 1001 Cara Menghasilkan Pupuk Organik. Lily Publisher. Yogyakarta

Zulkarnain, H. (2014). Dasar-Dasar

Hortikultura. Bumi Askara. Jakarta 
Raksun et al., Jurnal Bologi Tropis, 19 (1) : 19-24 DOI: $10.29303 /$ jbt.v19i1.1003 